\title{
In-Field Digital Photography and the Curation of Associated Records: Not All Prints Are Created Equal
}

\author{
Michelle K. Knoll (i) and A. Carver-Kubik
}

\section{ABSTRACT}

With the advent of commercially available digital cameras in the late 1990 s resulting in the near-exclusion of analog photographic prints today, most archaeological repositories around the world have a mix of analog and digital photographic prints. That ratio is increasingly moving toward digital print processes, of which there are several types. To minimize the loss of image quality, collection managers must become familiar with the unique curation challenges of photographic prints from digitally created images. Likewise, creators of digital content must be aware that choices made when selecting a print process for reposit will have a direct effect on image and print permanence. Site photographs are critical evidence of archaeological activity, and so the preservation of digital prints is in the interest, and is the responsibility, of collection managers and archaeologists alike.

Keywords: collections management, digital prints, conservation

Con la llegada de las cámaras digitales comerciales a finales de los años noventa, se eliminó casi por completo la impresión fotográfica analógica o tradicional. En el caso de los depósitos arqueológicos alrededor del mundo, probablemente se cuenta ya con un conjunto de impresiones fotográficas analógicas y digitales. Lo cierto es que los procesos de impresión digital van en aumento, por lo que es importante conocer los diversos procesos. Los administradores de colecciones deben aprender a enfrentarse a los desafíos de conservación únicos de las impresiones fotográficas de imágenes digitales para minimizar la pérdida de calidad de imagen. Del mismo modo, los creadores de contenido digital deben ser conscientes en la selección del proceso de impresión ya que este tendrá un efecto directo en la permanencia de la imagen y la impresión. Las fotografías de sitio son evidencia crítica de la actividad arqueológica. Por lo tanto, la conservación de las impresiones digitales es de interés y responsabilidad, tanto de los administradores de colecciones como de los arqueólogos.

Palabras clave: administrador de colecciones, impresiones digitales, conservacion

Up until the mid- to late 1990s, when the first consumer digital cameras were introduced, photographic collections in archaeology repositories ${ }^{1}$ mainly consisted of analog photographic prints (photographs made from chemically light-sensitive materials), such as an array of nineteenth-century processes and twentieth-century black/white and chromogenic (color) prints, negatives, and slides. Today, archaeological repositories around the world likely curate hard-copy photographs produced from a born-digital image (i.e., digital print) in their legacy collections or may even continue to require prints to supplement the digital image file. From the perspective of best practices for preserving visual information and photo documentation, having physical prints may be the optimal strategy for your institution. For archivists, born-digital records preserved in digital form are considered to be the original copy (Millar 2018:167-170). However, a paper copy can be insurance against disaster if staff are not trained in digital curation or do not have the necessary financial resources to curate digital images for the long term.
All collections-whether they include objects, born-digital or hard-copy photos, or some other medium-are susceptible to agents of deterioration (see Meister 2019). Born-digital photos, although not the focus of this article, make up an increasingly sizable part of any archaeological project. Some repositories have in-house trained personnel, the accompanying financial resources, and appropriate facilities, including the necessary hardware and software, to care for digital records and photos; they are able to handle the migration, backup, and safe electronic storage of such records. Most repositories, however, do not have these resources. The Heritage Health Information Survey Report released in February 2019 noted that "nearly two-thirds of archives reported damage or loss to their collections due to obsolete equipment causing loss of access to born digital information" (Institute of Museum and Library Services 2019). Many have rightfully argued that a "digital curation crisis" is slowly brewing and not receiving enough attention from the professional community (e.g., Eiteljorg 2004; Kintigh and Altschul 2010; Sullivan and Childs 2003:37-38). 
This article provides repository personnel and field archaeologists with recommendations to ensure the long-term preservation of digital prints. Because every archaeological project and repository is different and has varying numbers of personnel, levels of funding, and resources, we offer an approach to producing and caring for digital prints that can be easily adapted to these variables. We provide guidance for field archaeologists as they consider the creation of photo documentation for new projects during their prefield planning. In addition, we offer suggestions to repository personnel who curate digital prints or may be considering revising existing submission guidelines.

\section{PRINT PROCESSES AND CONSIDERATIONS FOR LONG-TERM CURATION OF DIGITAL PRINTS}

If you curate digital prints in your repository or if you are an archaeologist who is required to reposit prints as part of the associated records that you generate with an archaeological project, you should be aware that digital prints can have permanence issues under certain storage conditions that differ from the permanence issues affecting analog chromogenic prints. Some digital prints will fail under certain conditions, whereas others fare well under most conditions. The most important factors for creating and maintaining long-lasting digital prints are (1) using printing processes and materials required for making a goodquality print, (2) having the appropriate storage enclosures, and (3) ensuring compatibility between the digital print and repository storage conditions.

There are four main print processes used in digital photography: digitally exposed chromogenic, inkjet, digital electrophotography, and dye diffusion thermal transfer (D2T2; Table 1). It is likely that some combination of these processes is present in an archaeology repository that curates associated records.

\section{FIELD ARCHAEOLOGISTS AND THE CREATION OF DIGITAL PRINTS}

The permanence of digital prints depends both on those who create the prints and those who care for them. If a repository requires print copies as part of the submission guidelines, field archaeologists and collections staff should work together early in the project to discuss the repository's digital print process, labeling, and storage enclosure requirements and to determine if the repository accepts or requires both the digital files and digital prints that the archaeologists create. It is also important for the field archaeologist to consider the curation and other fees that are associated with the long-term care and preservation of both the digital files and digital prints. These considerations should be addressed during the prefield planning process, and appropriate funding for curation should be built in the overall project budget (Childs and Benden 2017). If the repository does not require the digital file, then it is the archaeologist's responsibility to ensure curation of the digital version in another digital archive, such as tDAR.

The first consideration in creating digital prints is the resolution of the original image file, which will determine, in part, the quality of the printed image and the size of the print. The general rule of thumb for printing digital images is that the file should be 300 pixels per inch (ppi) and the dimensions should be the same size as the final print (Johnson 2004:42). For example, the image file size for a $4 \times 6$-inch print should be 300 ppi and $4 \times 6$ inches.

There are a variety of acceptable methods for printing digital photographs, including instant photo kiosks, in-store or online photo-processing companies, and office desktop photo printers. These methods may produce prints using some or all of the current digital printing processes, each of which has different image quality and preservation concerns. Therefore, it is important to inquire about the printing technology before submitting a print order or making a print. You should also refer to the repository's submission guidelines before selecting a processing technology because they may dictate which type you must use. Instant photo kiosks are fast, easy, and economical. They typically produce D2T2 prints, but inkjet printers are also available. In-store or online services are also easy and fairly inexpensive, and they use all the current digital printing processes. Digitally exposed chromogenic and inkjet processes can produce a good image quality but have preservation challenges under certain environmental conditions. D2T2 prints have an acceptable image quality but lower than those produced by chromogenic or inkjet processes, regardless of the size of the image file. Digital electrophotographic prints have the lowest image quality.

Most home or office desktop photo printers are inkjet printers, but there are also electrophotographic and D2T2 desktop photo printers on the market. Creating digital prints from desktop inkjet printers seems simple but can be much more challenging than simply pressing "print": there are many considerations and a bit of a learning curve. The printer settings must be perfectly matched to the type of file being printed, and to the size and type of paper being used, so that the printer can apply the correct colors, mixture of colors, and volume of ink to the paper (Image Permanence Institute 2009a:5; Johnson 2004:247). To increase the likelihood of producing a long-lasting print, it is advisable to use original equipment manufacturer (OEM) products (i.e., the ink cartridges that come with the printer and paper made by the same manufacturer for that printer). The importance of compatibility between printer, ink, and paper support cannot be overstated. Wilhelm Imaging Research predicted, using accelerated aging processes, that prints produced by name-brand printers with OEM inks and papers will often last significantly longer than those produced with third-party products under the same conditions (Wilhelm 2007: Table 1).

\section{STORAGE ENCLOSURES FOR DIGITAL PRINTS}

Print stability is directly related to the handling of the print and the enclosure type, in addition to environmental conditions. Pigment-based inkjet prints are more prone to abrasions and scratches than other prints because the image is generally closer to the surface (Burge 2014:5; Image Permanence Institute 2004:5; Jürgens 2009:227). For this reason, polyester enclosures are recommended. For other types of prints, enclosures can be either plastic or paper, as long as they meet the requirements under the International Standard ISO 18902 Imaging materials_Processed 
TABLE 1. Digital Print Processes Most Commonly Found in Archaeological Repositories.

\begin{tabular}{ll}
\hline Processes & Description \\
\hline Digitally exposed silver halide & The first practical applications of digital printing technology exposed born-digital images to analog color \\
photographic papers. A computer signal activates an exposure unit (laser or light emitting diodes) to \\
expose light-sensitive photographic paper, which is then chemically processed to produce an image \\
composed of dyes. The paper support is resin coated. Digitally exposed chromogenic prints are still \\
commonly made by online and in-store printing services.
\end{tabular}

imaging materials_-Albums, framing and storage materials. Under this standard all materials shall have passed the Photographic Activity Test (PAT). Paper-based materials also need to be acidfree and lignin-free with a Kappa number of 7 or lower. Buffered papers should have an alkali reserve of at least $2 \%$ calcium carbonate. Storage materials with a colorant should also have passed the bleed test.

Polyvinyl chloride (PVC) should never be used for photographic prints (Holmes 2017); its use is particularly problematic for digital electrophotographic prints because the plasticizers in the sheets can soften the toner and pull it from the surface of the print (Digital Print Preservation Portal 2018a). Polyethylene enclosures, which are effective against moisture absorption, do not prevent damaging pollutants from landing on prints. Polyester and polypropylene enclosures are better choices (Fenn 2003:33).

Blocking-prints adhering to one another or to storage enclosures-can result in color transfer, delamination, and other types of surface damage (Rima and Burge 2009). Allow new inkjet prints to fully dry for 24 hours after printing before placing in enclosures, and ensure image sides do not touch each other to minimize the damage caused by blocking (Image Permanence Institute 2018:20; Jürgens 2009:228).

\section{Recommendations for Field Archaeologists}

- Communicate with the repository staff or review the repository's submission guidelines before you create digital prints as part of a new archaeological project. The repository may not accept digital prints or, if it does, may not be able to curate all print processes that are available.

- If the repository does not have the capacity to care for borndigital records and photos, make arrangements with a digital archive for preservation of those records.
- Whether using a photo kiosk or an in-store or online printing service, know what type of print is being made. Report the make and model of the printer used to the repository. This "metadata" will be useful to the repository for collection management and curation purposes.

- If using a desktop printer, educate yourself on how to make good prints (Horenstein 2011; Johnson 2004; Salvaggio et al. 2009) and use OEM materials.

- Follow print enclosure recommendations per the repository guidelines and best practices.

\section{REPOSITORY STAFF AND THE CURATION OF DIGITAL PRINTS}

If you have digital prints in your legacy collections, you should be familiar with the various print processes, know how to identify these processes, and understand print storage requirements. If you accept digital prints, your repository guidelines should ensure compatibility between the print process and your storage-room conditions. Fortunately, the availability of multiple processes provides you with an opportunity to exert control over what is accessioned into your collections.

Identifying the printing processes used to create the digital prints in your collection will allow you to mitigate their potential deterioration under suboptimal storage conditions. Each process has its own key identifying features that can been seen using different lighting techniques and magnification. To learn a step-by-step approach for print identification, view the process identification videos on Graphics Atlas, www.graphicsatlas.org, or the free webinars at www.imagepermanenceinstitute.org/process-id-webinars. Magnification is necessary to identify digital prints. There are several good-quality and inexpensive loupes and pocket microscopes 

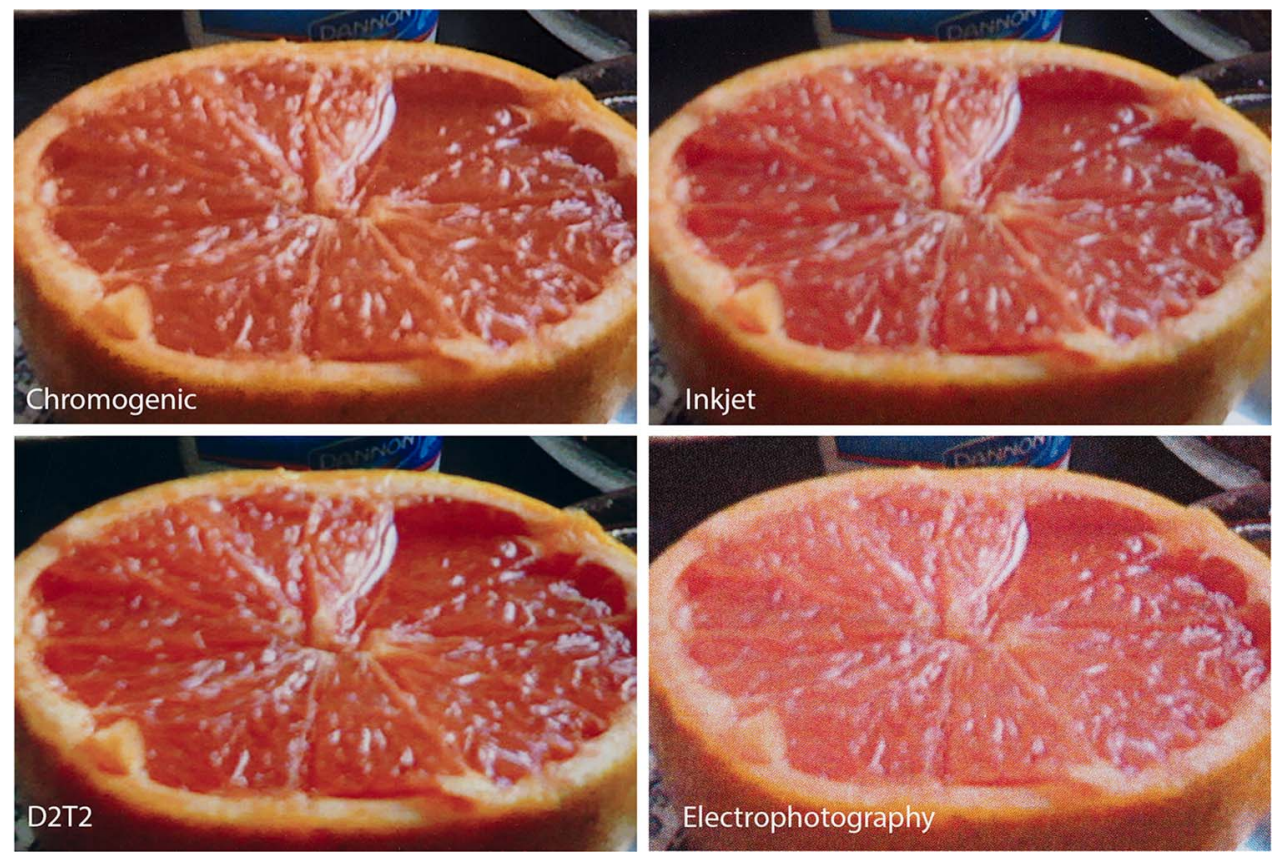

FIGURE 1. Four different digital print processes of the same image. Notice the variations in image quality. Images courtesy of the Image Permanence Institute.

available on the market that will be sufficient for this purpose. Loupes are usually 10x magnification, and pocket microscopes should be 60x-120x magnification. Figures 1, 2, and 3 illustrate each digital print process at increasing levels of magnification.

\section{Digitally Exposed Chromogenic}

Digitally exposed chromogenic prints have a resin coated (RC) paper support that feels slick and plastic-like on the back. Usually, the name of the manufacturer or product is printed on the back; sometimes the image file name is also printed there. The color of a new print should look balanced and correct. Older prints may exhibit a shift in color, appearing to have a magenta or cyan cast and yellow highlights. The surface sheen of most chromogenic prints is glossy with an even gloss all over. Some have a slight applied texture that will alter the gloss. With low magnification the image will appear continuous in tone, meaning there is no pattern to the image, such as dots. With high magnification, small pinpricks of color called dye clouds may be visible. Digitally exposed chromogenic prints may also have a slight pattern to the dye clouds: for example, they may line up in rows or have a slight grid pattern.

\section{Inkjet}

An inkjet print with a good image quality looks and feels like a true analog photograph. Inkjet prints typically have a "photo" support of either an RC or a baryta paper. An RC support is slick and has a plastic feel to the back. Prints may have dye-based or pigment-based inks or a combination of both. There are two types of image-receiving layers (IRLs) - polymer and porous - that hold the ink image. The back of RC papers with a polymer IRL usually feels coarse like sandpaper because of the presence of antiblocking agents that prevent them from sticking to each other. The product or manufacturer name may be printed on the back.
Inkjet prints may have several surface characteristics that can be observed at the surface view. Prints on photo papers are usually glossy or semiglossy. Prints made with dye-based inks have an even gloss, whereas prints made with pigment-based inks may exhibit a difference in gloss between the shadows and the highlights, called differential gloss. Pigment-based inkjet on a glossy surface may also exhibit bronzing, in which the color of the gloss in the shadows is the color bronze. Finally, at the magnification view, inkjet prints are composed of a random pattern of small dots (called an FM screen). The dots are usually cyan, magenta, yellow, and black, but other secondary colors may be visible if the dots overlap or an expanded ink set was used.

\section{Dye Diffusion Thermal Transfer}

These prints may look and feel like analog color photographs but likely have a lower-quality image. They have an RC paper support and may have the product or manufacturer's name printed on the back. They are glossy with an even gloss. With magnification they are extremely diffuse and very difficult, if not impossible, to focus on. A blurry grid pattern may be visible.

\section{Digital Electrophotography}

Electrophotographic prints are made up of dots, similar in size to those on lithographic prints. Therefore, the image may be relatively low quality. The paper may be uncoated plain office paper or a coated support with a coating on one side or both. Prints often exhibit differential gloss, particularly on glossy papers. With magnification, the image is made up of a regular pattern of dots. However, the pattern of the dots depends on two variables: (1) printer design, because there are variations within digital electrophotographic technologies, and (2) toner type: dry or liquid. Most desktop printers and some online print-on-demand services 

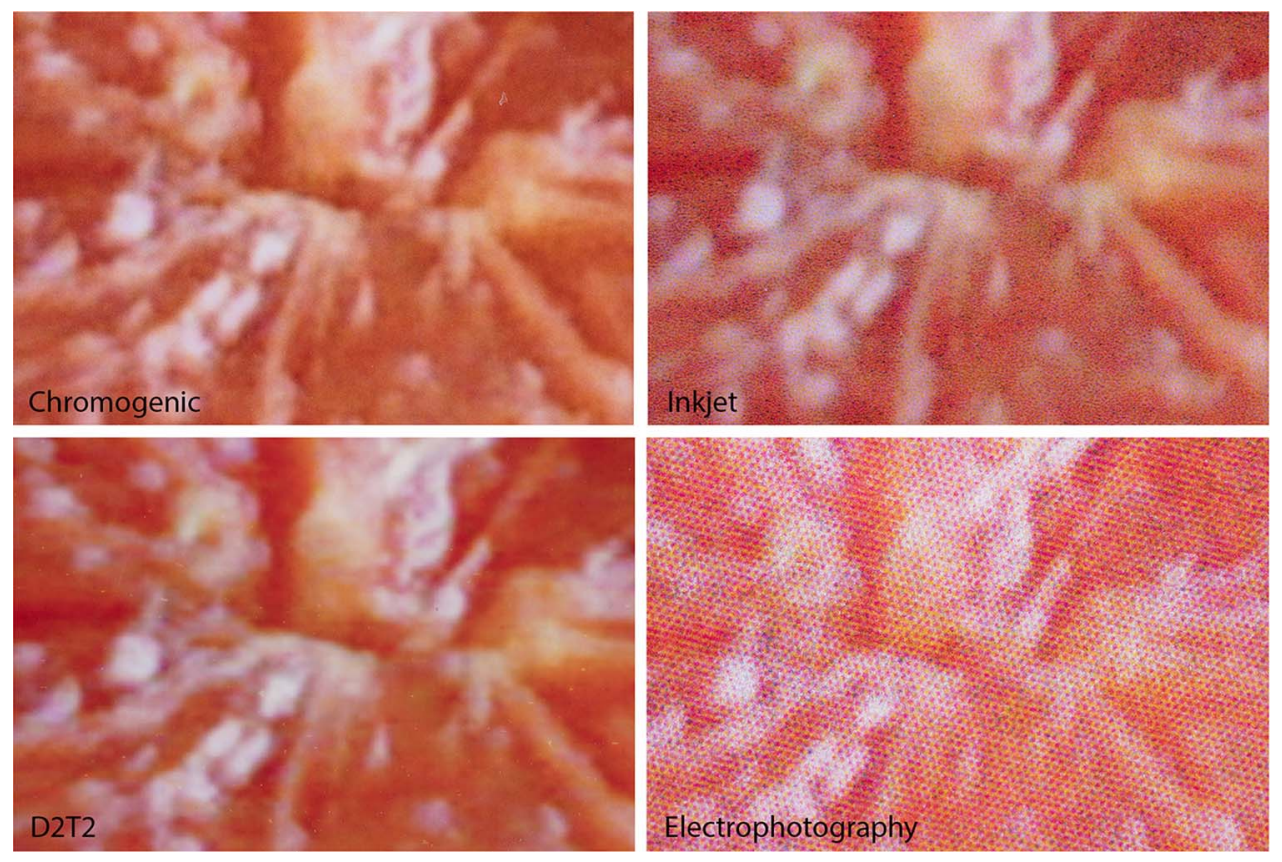

FIGURE 2. 10x magnification (loupe): chromogenic and D2T2 prints are continuous in tone, inkjet prints are made up of very small dots, and electrophotographic prints are made up of large dots. Images courtesy of the Image Permanence Institute.
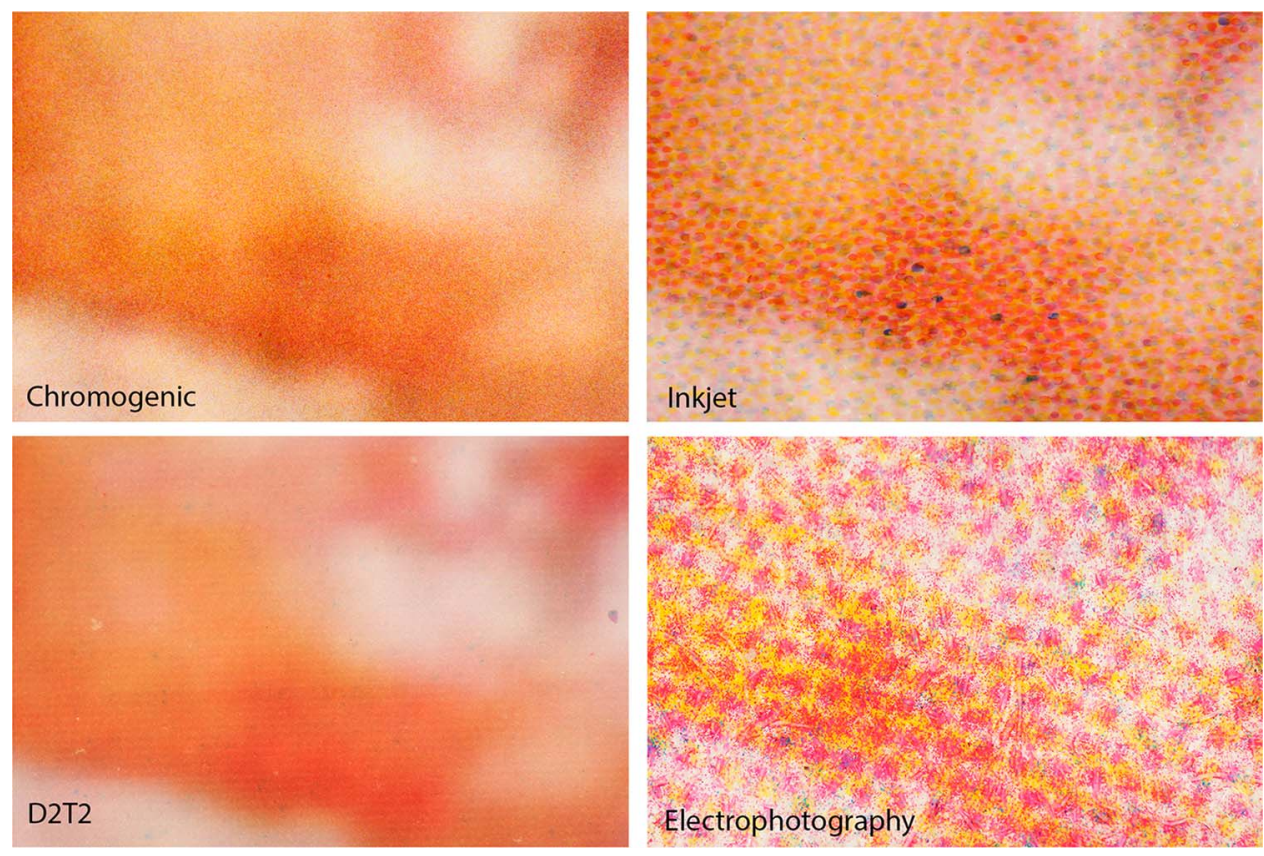

FIGURE 3. 50x magnification (pocket microscope): dye clouds are visible in chromogenic prints, D2T2 prints are very diffuse with a slight grid pattern, inkjet dots are clearly visible, and electrophotographic dots are large and dusty, indicating it is a dry toner electrophotographic print. Images courtesy of the Image Permanence Institute.

use dry toner. Dry toner dots appear rough and dusty, and the dots are in a regular pattern, usually of rosettes (AM screen) or parallel lines. Color prints have cyan, magenta, yellow, and black dots or lines. Some online print-on-demand services use liquid toner. These dots are fairly smooth and likely have a rosette pattern as well. 
TABLE 2. Temperature and Relative Humidity Recommendations for Born-Digital Prints.

\begin{tabular}{|c|c|c|c|c|c|}
\hline \multirow{2}{*}{$\begin{array}{l}\text { STORAGE } \\
\text { CONDITIONS }\end{array}$} & \multirow{2}{*}{ TEMP $^{\circ} \mathrm{C}$} & $\begin{array}{l}\text { DIGITALLY } \\
\text { EXPOSED }\end{array}$ & \multicolumn{3}{|c|}{ Digitally Printed Photographs } \\
\hline & & CHROMOGENIC & INKJET & D2T2 & ELECTROPHOTOGRAPHY \\
\hline ROOM & $20^{\circ} \mathrm{C}$ & NO & NO & GOOD & GOOD \\
\hline COOL & $12^{\circ} \mathrm{C}$ & NO & FAIR & VERY GOOD & VERY GOOD \\
\hline COLD & $4^{\circ} \mathrm{C}$ & GOOD & GOOD & VERY GOOD & VERY GOOD \\
\hline FREEZING & $<0^{\circ} \mathrm{C}$ & VERY GOOD & VERY GOOD & VERY GOOD & VERY GOOD \\
\hline NO & Likely to caus & snificant damage & & & \\
\hline FAIR & Does not me & commendations b & lay be satisfac & for extended $p$ & \\
\hline GOOD & Meets minim & recommendations & & & \\
\hline VERY GOOD & Exceeds minc & $\mathrm{m}$ recommendatio & & & \\
\hline
\end{tabular}

Noted: Adapted from Burge (2014:Table 3).

\section{CARING FOR DIGITAL PRINTS}

The primary forces that can cause deterioration of digital prints are heat, high relative humidity $(\mathrm{RH})$, airborne pollutants, and, when on display, ultraviolet (UV) radiation (Burge et al. 2010; Fenn 2003; Image Permanence Institute 2004, 2009b; Jürgens 2009; Rima and Burge 2009; Venosa et al. 2011). Since 2007, the Image Permanence Institute (IPI) has been testing the permanence of born-digital prints using accelerated aging methods under these conditions. Results of these tests have led researchers at IPI to reach five significant conclusions: (1) digitally printed photographs are highly variable in their sensitivity to deterioration forces, (2) cold storage significantly reduces deterioration rates in inkjet and chromogenic prints, (3) prints made with pigment inkjet can be very sensitive to abrasion, (4) inkjet dyes can bleed when exposed to high humidity, and (5) prolonged exposure to the primary forces that can cause deterioration can cause image fading and support damage in both dye- and pigment-based inkjet photographs with either a polymer or porous IRL (Burge 2014:1). These changes have been observed in chromogenic prints for decades and are now being observed in digital prints as well. However, nonchromogenic digital prints tend to fare better in dark storage than do chromogenic (both analog and digitally exposed) prints.

Caring for digital prints can be less costly than caring for chromogenic prints, depending on the print process and your storage environment. Many of the storage requirements for chromogenic prints (i.e., freezing temperatures) will also benefit digital prints but are not required in every instance. Cooler temperatures generally slow down chemical deterioration.
Recommended temperature set points (Table 2) should be considered as guides for temperature ranges.

\section{Digitally Exposed Chromogenic Prints}

Digitally exposed chromogenic prints have the same deterioration issues as analog chromogenic prints. While typically of excellent image quality, all chromogenic prints will show fading or discoloration after about 50 to 100 years in dark storage at room temperature. Exposure to light and heat will accelerate that degradation (Reilly 1998). Storage temperatures should be, at a minimum, $4^{\circ} \mathrm{C}$ to meet minimum recommendations for long-term storage with an $\mathrm{RH}$ of $30 \%-50 \%$ (Burge 2014:Table 3; Digital Print Preservation Portal 2018b:Table 3).

\section{Inkjet Prints}

The three main changes observed during accelerated aging tests of inkjet prints are fading of the colorants, migration or bleeding of dye colorants, and yellowing and embrittlement of the paper substrate. Color fading, consisting of overall fading of an image and a hue shift, is caused by high temperature, light, and pollutants (Figure 4). Ozone pollution is especially problematic for inkjet prints, which should not be exposed to the open air for extended periods (Burge et al. 2010:5). Inkjet prints are more susceptible to warm temperature than other digital processes. Storage temperatures should be, at a minimum, $4^{\circ} \mathrm{C}$ to meet minimum recommendations for long-term storage (Burge 2014: Table 3; Digital Print Preservation Portal 2018b:Table 3). 


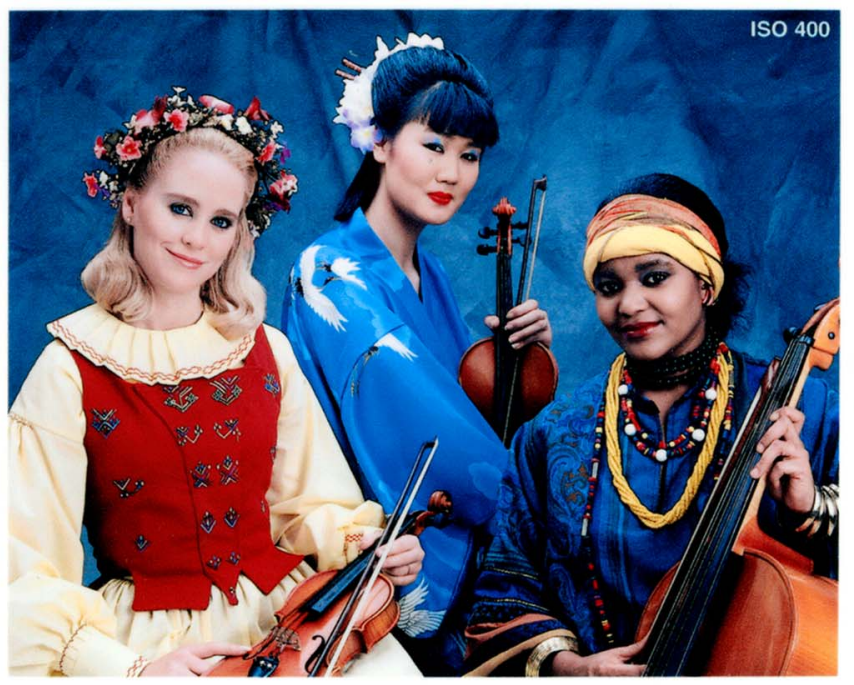

$\mathrm{a}$

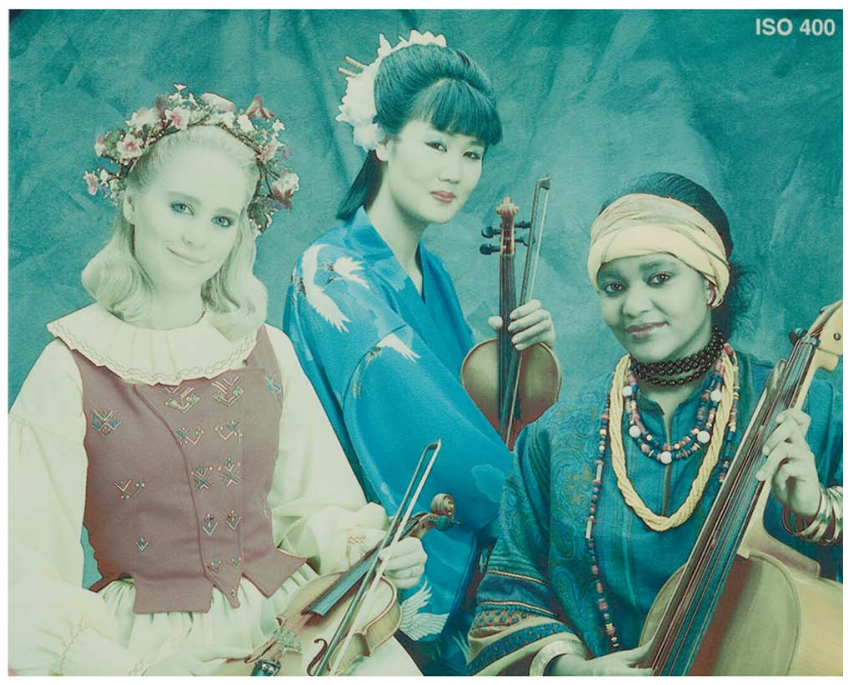

b

FIGURE 4. Inkjet prints showing examples of (a) the original print and (b) after fading and hue shift. Images courtesy of the Image Permanence Institute.

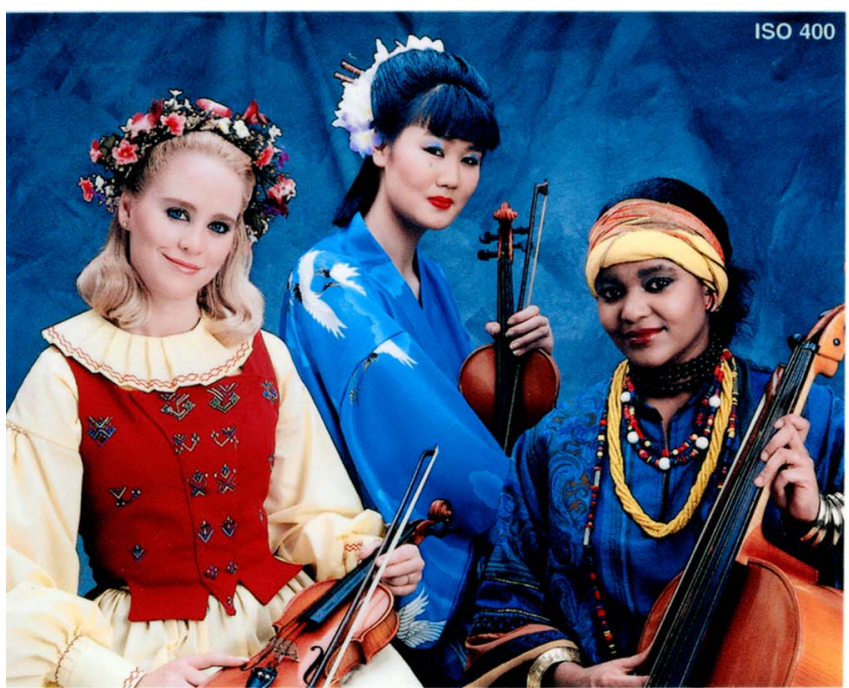

a

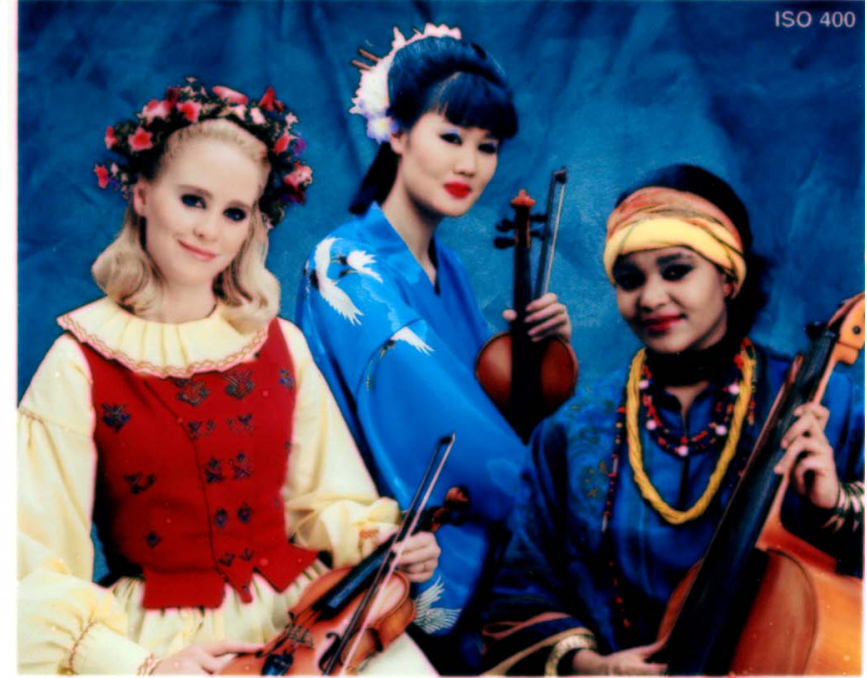

b

FIGURE 5. Inkjet prints showing examples of (a) the original print and (b) after dye migration. Images courtesy of the Image Permanence Institute.

IPI recommendations for relative humidity ranges from $30 \%$ to $50 \%$ for all photographic prints. High humidity can cause mold growth, ferrotyping-softening of the print surface that causes an uneven degradation of the glossy surface, blocking-prints adhering to one another or to storage enclosures, and dye migration. Dye migration of dye-based inkjet under conditions of high $\mathrm{RH}$ will result in the loss of clarity, color fringing - the bleeding of a single colorant in a multiple color image in which the bled color appears strongly at the edges, and migration of dyes across the surface (Figure 5) or onto other prints in a stack (Digital Print Preservation Portal 2018a; Image Permanence Institute 2009b:2). Dye migration is unique to dye-based inkjet prints. A dye image can be significantly altered in as little as one to seven days with 75\%-80\% $\mathrm{RH}$ at $25^{\circ} \mathrm{C}$ depending on the IRL type (Burger and Burge 2018). Conversely, humidity below $30 \%$ can cause surface coatings to become more fragile.

Yellowing may occur in the support caused by changes in the optical brightening agents (if present) with exposure to pollutants (Burge 2014:2), heat, and humidity (Nishimura et al. 2013). In general, inkjet prints made with pigment-based inks are more resistant to poor environmental conditions and are more lightfast. Prints made with dye-based inks are more susceptible to image fading and image bleeding. Papers with a polymer IRL usually, but 
not always, have a dye-based image and are more resistant to abrasions and fading from pollutants but are sensitive to image bleeding when exposed to high humidity (Burge 2014:8).

Pressure-sensitive adhesives (PSAs) and poor-quality paper should never be used with inkjet prints because they can cause yellowing in a matter of months (Burge 2014:5). Avoid storing inkjet prints in direct contact with traditional prints because some inkjet prints may induce yellowing of analog photographic prints and analog prints may abrade the more sensitive born-digital prints (Burge 2014:4).

\section{Digital Electrophotographic Prints}

Digital electrophotographic prints are generally considered stable - or as stable as the paper on which they are printed. Poor-quality paper may become yellow and brittle with high temperatures and high relative humidity. In contrast, the colorant in black toner is carbon black and is very stable. Color toners vary between manufacturers and, as such, are less predictable but overall tend to be fairly stable. Digital electrophotographic prints are sensitive to heat and pressure, which may result in blocking. Blocking under high $\mathrm{RH}$ conditions can result in color transfer, delamination, and other types of surface damage. Digital electrophotographic prints on good quality paper are stable in dark storage at $20^{\circ} \mathrm{C}$ and an $\mathrm{RH}$ of 30\%-50\% (Burge 2014:Table 3; Digital Print Preservation Portal 2018b:Table 3).

\section{Dye Diffusion Thermal Transfer Prints}

Dye diffusion thermal transfer prints are moderately light sensitive and can fade at or near the rate of chromogenic prints if they are not stored in the dark. Light can also cause the polyethylene layer of the RC support to crack. They are stable in dark storage at $20^{\circ} \mathrm{C}$ and an $\mathrm{RH}$ of $30 \%-50 \%$. However, D2T2 prints made before the introduction of the protective topcoat in 1994 are very sensitive to light, heat, pressure, water, pollution, and fingerprints (Burge 2014:Table 3; Digital Print Preservation Portal 2018b:Table 3).

\section{Recommendations for Repository Staff}

- For incoming reposits: Electrophotographic and D2T2 processes are more stable at room temperature; however, they have a lower image quality than prints produced by digitally exposed chromogenic and inkjet, and fine image details are lost. Digitally exposed chromogenic and inkjet prints have a higher image quality with more details but require cold storage conditions. Consider these factors when establishing print process requirements in your repository guidelines.

- For legacy collections: If you have digitally exposed chromogenic or inkjet prints in your legacy collections, and your repository does not have cold or frozen storage, consider reprinting the photos from the original file in a more stable process (D2T2 and electrophotographic), keeping in mind the first recommendation.

- Request enclosures that have passed the requirements for ISO 18902 for all prints. Repositories in areas that are susceptible to high humidity and warm temperatures should consider using paper enclosures and avoid overstuffing prints where pressure can cause blocking. If pollution is an issue and inkjet prints are in your collection, then inert plastic enclosures may be more suitable.

\section{CONCLUSION}

Digital prints have been present in legacy collections around the world since the mid- to late 1990s and are still being accessioned as new collections along with their digital image file counterparts. Repository staff and field archaeologists should work together early on in the process before new collections are generated. They should communicate about appropriate print and storage methods, as well as necessary funding resources to care for collections for the long term.

Repository staff should take steps to ensure that existing digital print collections are preserved if they intend to retain the prints as part of the accessioned collection. For the long-term permanence of digital images, the print process, storage enclosures, and storage room conditions must be carefully considered as a package. If digital prints continue to be required with the reposited associated records, collections staff should be realistic about what level of care they can provide and reflect that reality in their repository guidelines.

Field archaeologists should also budget appropriately for longterm care and management of both born-digital and hard-copy derivations of photos and other associated records and need to communicate with repository personnel about submission requirements. These are important considerations for the prefield planning stages of an archaeological project. The recommendations in this article should inform the choices that field archaeologists make before they print and store photographic documentation of the archaeological record; these decisions have long-term consequences for the preservation of that record.

\section{Acknowledgments}

We wish to thank three anonymous reviewers and Danielle Benden for providing useful feedback on this article. We also thank Fanny Blauer for assistance with Spanish-language translations. We are grateful to colleagues at Image Permanence Institute, Daniel Burge and Jennifer Burger, for their research and expertise in digital print materials.

\section{Data Availability Statement}

No original data were presented in this article.

\section{NOTE}

1. The definition of the term repository (or archaeological repository) as it appears in this article is taken from the Archaeological Collections Consortium article (2016) entitled "Building Common Ground on Collections: An Initial Glossary of Collections-Related Terminology," published in The SAA Archaeological Record 16(1):41-43: "a facility or institution that professionally manages collections on a long-term basis." 


\section{REFERENCES CITED}

Archaeological Collections Consortium

2016 Building Common Ground on Collections: An Initial Glossary of

Collections- Related Terminology. SAA Archaeological Record 16(1):41-43.

Burge, Daniel

2014 IPI Guide to Preservation of Digitally-Printed Photographs. Electronic document, http://www.dp3project.org/webfm_send/739, accessed July 23, 2018.

Burge, Daniel, Nino Gordeladze, Jean-Louis Bigourdan, and Douglas Nishimura 2010 Effects of Ozone on the Various Digital Print Technologies: Photographs and Documents. Journal of Physics: Conference Series 231(012001):1-6.

Burger, Jennifer, and Daniel Burge

2018 A Guide for the Assessment and Mitigation of Bleed, Gloss Change, and Mold in Inkjet Prints during High-Humidity Conditions. Paper presented at the International Symposium on Technologies for Digital Photo Fulfillment, Dresden, Germany. Electronic document, http://www.dp3project.org/ webfm_send/810, accessed on January 17, 2019

Childs, S. Terry, and Danielle M. Benden

2017 A Checklist for Sustainable Management of Archaeological Collections. Advances in Archaeological Practice 5(1):12-25.

Digital Print Preservation Portal

2018a Selecting Enclosures. Electronic document, http://www.dp3project.org/ preservation/storage-enclosures, accessed October 18, 2018.

2018b Storage Recommendations. Electronic document, http://www.dp3project.org/preservation/storage-recommendations, accessed October 18, 2018

Eiteljorg, Harrison, II

2004 Archiving Digital Archaeological Records. In Our Collective Responsibility: The Ethics and Practice of Archaeological Stewardship, edited by S. Terry Childs, pp. 67-76. Society for American Archaeology, Washington, DC.

Fenn, Julia

2003 Poisons, Plastics, and Paper Potentially Destructive Combinations in Archival Storage. ESARBICA 22:25-36.

Holmes, Sara

2017 The Problem of Plastic: A Sometimes Sticky Situation. MAC Newsletter 44(4), Article 10:26-27. Electronic document, https://lib.dr.iastate.edu/cgi/ viewcontent.cgi?article $=1049 \&$ context $=$ macnewsletter, accessed October 17, 2018.

Horenstein, Henry

2011 Digital Photography: A Basic Manual. Little, Brown, New York. Image Permanence Institute

2004 A Consumer Guide to Traditional and Digital Print Stability. Electronic document, https://www.imagepermanenceinstitute.org/webfm_send/313, accessed September 26, 2018

2009a A Consumer Guide to Modern Photo Papers. Electronic document, https://www.imagepermanenceinstitute.org/webfm_send/310, accessed September 27, 2018

2009b A Consumer Guide to Understanding Permanence Testing. Electronic document, https://www.imagepermanenceinstitute.org/webfm_send/311, accessed September 27, 2018

2018 IPI's Guide to: Preservation of Digitally Printed Images. Electronic document, http://www.dp3project.org/webfm_send/886, accessed February 26, 2019
Institute of Museum and Library Services

2019 Heritage Health Information Survey (HHIS) Report: A Snapshot of Facts \& Figures. Electronic document, https://www.imls.gov/sites/default/files/hhissnapshot.pdf, accessed March 21, 2019

Johnson, Harald

2004 Mastering Digital Printing. 2nd ed. Muska \& Lipman, Cincinnati, Ohio. Jürgens, Martin C.

2009 The Digital Print: Identification and Preservation. Getty Conservation Institute, Los Angeles.

Kintigh, Keith W., and Jeffrey H. Altschul

2010 Sustaining the Digital Archaeological Record. Heritage Management 3(2): 264-274

Meister, Nicolette

2019 A Guide to the Preventive Care of Archaeological Collections. Advances in Archaeological Practice 7(3)DOI:10.1017/aap.2019.7

Millar, Laura A.

2018 Archives: Principles and Practices. 2nd ed. Facet, London.

Nishimura, Douglas, Daniel Burge, Jean-Louis Bigourdan, and Nino Gordeladze

2013 Reanalysis of Yellowing of Digitally Printed Materials in Cultural Heritage Collections. Book and Paper Group Annual 32:123-128.

Reilly, James M.

1998 Storage Guide for Color Photographic Materials. Electronic document, https://www.imagepermanenceinstitute.org/webfm_send/517, accessed January 11, 2019.

Rima, Lindsay, and Daniel Burge

2009 Tendency of Digitally Printed Materials to Ferrotype or Block. Society fo Imaging Science and Technology, Technical Program and Proceedings. Electronic document, http://www.dp3project.org/webfm_send/553, accessed on October 13, 2018.

Salvaggio, Nanette, Leslie Stoebel, and Richard Zakia

2009 Basic Photographic Materials and Processes. 3rd ed. Focal Press, Burlington, Massachusetts.

Sullivan, Lynne P., and S. Terry Childs

2003 Curating Archaeological Collections: From the Field to the Repository. AltaMira Press, Lanham, Maryland.

Venosa, Andrea, Daniel Burge, and Douglas Nishimura

2011 Effect of Light on Modern Digital Prints: Photographs and Documents. Studies in Conservation 56(4):267-280

Wilhelm, Henry

2007 A Survey of Print Permanence in the $4 \times 6$-Inch Consumer Digital Print Market in 2004-2007. Electronic document, http://wilhelm-research.com/ist/ ist_2007_03.html, accessed October 5, 2018.

\section{AUTHOR INFORMATION}

Michelle K. Knoll N Natural History Museum of Utah, University of Utah, 301 Wakara Way, Salt Lake City, UT 84124, USA (mknoll@nhmu.utah.edu, corresponding author) https://orcid.org/0000-0002-6518-3616

A. Carver-Kubik Image Permanence Institute, Rochester Institute of Technology, 70 Lomb Memorial Drive, Rochester, NY 14623, USA 